\title{
Hodgkin's Disease
}

\author{
AN IMMUNODEPLETING AND IMMUNOSUPPRESSIVE DISORDER \\ Jeremiah J. Twomey, Arline H. Laughter, Sandra Farrow, and \\ Charles C. Douglass
}

From the Department of Medicine, Baylor College of Medicine, the Veterans

Administration and the Methodist Hospitals, Houston, Texas 77031

\begin{abstract}
A B S T R A C T Irradiated leukocytes or mononuclear leukocytes, from 16 out of 30 patients with Hodgkin's disease and from one patient with the Sézary syndrome, stimulated in culture subnormal $\left[{ }^{3} \mathrm{H}\right]$ thymidine incorporation by allogeneic lymphocytes from normal individuals. This abnormality was not demonstrated in any of 30 other patients with non-Hodgkin's lymphomas. Subnormal mixed leukocyte culture reaction activation was caused by suppression of the mixed leukocyte reaction by patients' cells. Inhibition of the reaction by patient mononuclear leukocytes was corrected when adherent cells were removed or when protein synthesis was inhibited with cycloheximide. The inhibitory cells were probably lymphocytes since selective removal of phagocytic cells did not remove the inhibition by other patient mononuclear leukocytes. The presence in culture of as few as 2,500 granulocytes per $\mathrm{mm}^{3}$ also reduced responses when target cells were from patients with Hodgkin's disease. Patient cells no longer suppressed the mixed leukocyte reaction after patients entered clinical remission which suggests that suppression is a reversible, disease-related abnormality. Thus, the immune deficiency with advanced Hodgkin's disease caused by lymphocyte depletion may be compounded by a relative excess of suppressor lymphocytes. The overall immunodeficiency may be further compounded by suppression of immune responses by granulocytes at even physiologic concentrations.
\end{abstract}

\section{INTRODUCTION}

Lymphocyte depletion of lymphoid tissues (1), peripheral lymphopenia (2), and both in vivo $(2,3)$ and in

Preliminary reports on this work were published: 1973. Proc. Leucocyte Cult. Conf. 7: 627-642, and 1973. J. Natl. Cancer Inst. 51 : 345-351.

Received for publication 10 February 1975 and in revised form 14 April 1975. vitro (4-9) impairment of immune responses may occur with Hodgkin's disease. This acquired immunodeficiency primarily affects cell-mediated immunity $(10,11)$ and is associated with increased susceptibility to infections (12) and accelerated tumor expansion (2).

A number of mechanisms could contribute to the immunodeficiency with Hodgkin's disease: $(a)$ Direct involvement of immunoreactive cells in the neoplastic process could result in their functional impairment (13) or critical restriction in the range of their responses (14). (b) A deficiency of immunobiologically active substances, (e.g. thymic products) which are needed to sustain (15) as well as to develop immune competence, could lead to lymphocyte depletion. (c) An excess of suppressor cells or of their functional impact $(16,17)$ relative to effector cells could inhibit immune responses. (d) Occasionally, plasma from patients with Hodgkin's disease contains lymphocytotoxic antibody (18) or otherwise inhibits lymphoproliferative responses (19).

This laboratory has reported that irradiated leukocytes from some patients with Hodgkin's disease do not stimulate normal responses in the mixed leukocyte culture reaction $(M L R)^{1}$ even when responder lymphocytes are from healthy allogeneic individuals $(20,21)$. An inability to stimulate normal MLR responses has since been reported with the Sézary syndrome in man (22) and with lymphoid leukemia in AKR mice (23).

The present report concerns MLR stimulation with Hodgkin's disease and other lymphoproliferative disorders. The data show a direct relationship between Hodgkin's disease and subnormal MLR stimulation;

\footnotetext{
${ }^{1}$ Abbreviations used in this paper: MLR, mixed leukocyte culture reaction; MNL, mononuclear leukocytes ; MNLx, irradiated mononuclear leukocytes; $T$ cells, thymusderived lymphocytes; B cells, bursa of Fabriciis equivalent derived lymphocytes.
} 
this abnormality is probably caused by suppression of the response by patient leukocytes.

\section{METHODS}

Subjects. A histologic diagnosis was made on each patient with Hodgkin's disease or lymphocytic lymphoma. Hodgkin's disease was classified histologically (1) and staged clinically (24) with lymphangiography and laparotomy performed on selected patients. Patients with lymphocytic lymphoma had no light microscopic evidence of blood or bone marrow involvement. Chronic lymphocytic leukemia was diagnosed by an absolute lymphocyte count $z$ 18,000 per $\mathrm{mm}^{3}$ of blood with lymphocytes comprising $230 \%$ of cells in bone marrow aspirates. Between 10 and $15 \%$ of circulating lymphoid cells from the patient with the Sézary syndrome had the morphology of Sézary cells. Immunologically normal blood was obtained from healthy volunteers or patients awaiting elective surgery (e.g. herniorraphy) or convalescing from myocardial infarction. Henceforth, these are referred to as normal subjects and their cells as normal cells. Since a decline in MLR reactivity has not been observed in our culture system through the ninth age decade, no attempt was made to agematch patient and normal test subjects.

Definitions. (a) Cell preparations: Leukocytes included all white blood cells harvested with leukocyte-rich plasma. Mononuclear leukocytes (MNL) included lymphocytes, monocytes, and $\leq 5 \%$ granulocytes; these cells were separated from whole blood by floatation. The term lymphocytes refers to cells derived from MNL preparations after they were depleted of phagocytic cells.

(b) MLR stimulation: The protocol used to test for MLR stimulation was as follows (numbers in parentheses represent lymphocytes added per culture): Test MNL $_{x}$ $(100,000)$ stimulating allogeneic normal MNL preparation A; Test $\mathrm{MNL}_{\mathbf{x}}(200,000)$ stimulating allogeneic normal MNL preparation A; Test $\mathrm{MNL}_{\mathbf{x}}(100,000)$ stimulating allogeneic normal MNL preparation B; Test MNLx (200,000) stimulating allogeneic normal MNL preparation $B$. The highest $\left[{ }^{3} \mathrm{H}\right]$ thymidine incorporation stimulated by test $\mathrm{MNL}_{\mathbf{x}}$ in these four culture systems minus spontaneous incorporation by separate cultures of the responding and stimulating cells was recorded.

(c) Stimulation ratio: This expression was introduced so as to permit comparison of $\left[{ }^{3} \mathrm{H}\right]$ thymidine incorporation by constant numbers of responder lymphocytes when stimulated with two standard numbers of test target $\mathrm{MNL}$. Ratios were derived as follows: Stimulation ratios $=(\mathrm{Re}-$ sponses stimulated by 100,000 MNL - -lymphocytes)/(responses stimulated by $200,000 \mathrm{MNL}$-lymphocytes). The pair of responses by normal MNL preparation A or B which included the highest $\left[{ }^{3} \mathrm{H}\right]$ thymidine incorporation stimulated by test MNL was selected for ratio analysis.

Preparation of cells. (a) Leukocytes were harvested with plasma after spontaneous red cell sedimentation at room temperature. (b) MNL were separated from heparinized blood by floatation on a mixture of Ficoll (Pharmacia Fine Chemicals, Inc., Piscataway, N. J.) and $\mathrm{Na}$ diatrizoate (Hypaque, Winthrop Laboratories, New York) (25) ; lymphocyte recovery exceeded $70 \%$ and viability by trypan blue exclusion exceeded $95 \%$. (c) Lymphocytes were purified from MNL with a magnetic lymphocyte separator (Technicon lymphocyte separator, Technicon Instruments Corp., Tarrytown, N. Y.) ; about $50 \%$ of the original MNL lymphocytes were recovered and $<0.5$ of these cells were monocytes. (d) Granulocyte preparations, which included
$<4 \%$ lymphocytes, were separated from leukocyte-rich plasma by centrifugation through Ficoll-Hypaque. (e) Target cells in one-way-stimulating MLR tests received 1,500 rads of $\mathrm{X}$-irradiation at 500 rads, per $\min <1 \mathrm{~h}$ before they were added to cultures except in specified experiments where stimulation was with mitomycin C (Sigma Chemical Co., St. Louis, Mo.) pretreated MNL (26). Inhibition of $\left[{ }^{3} \mathrm{H}\right]$ thymidine incorporation by irradiation or mitomycin C pretreatment of target cells was routinely verified by culturing them with irradiated allogeneic MNL (MNL $)$. (f) Adherent suppressor cells were removed by preincubating MNL with glass wool (27).

Enzymatic pretreatments of $M N L$. In preliminary experiments, 4-5 $\times 10^{8} \mathrm{MNL}$ from normal subjects were incubated for $15 \mathrm{~min}$ with $0.1-0.3 \mathrm{U}$ of neuraminidase (Calbiochem, San Diego, Calif.) (28) or with $500-1,500 \mu \mathrm{g}$ of protease (Sigma Chemical Co.) (29) in 1-ml volumes; these cells were then washed, irradiated, and used to stimulate in the MLR. Stimulation was comparable using enzymatically pretreated and untreated $\mathrm{MNL}_{\mathbf{x}}$. In this study, pretreatments were with $0.15 \mathrm{U}$ of neuraminidase and $1,000 \mu \mathrm{g}$ of protease. In other experiments, suppressor cell activity was inhibited by preincubating MNL with cycloheximide (Sigma Chemical Co.) as described by Folch and Waksman (30). Pretreated cells were washed three times before they were added to cultures.

Culture techniques. Two different culture techniques were used. (a) Cultures that provided MLR stimulation results listed in Table I, group B, and to measure MLR responses by the same cell preparations, were in plastic petri dishes (Falcon Plastics, Div. of BioQuest, Oxnard, Calif.) and were on leukocyte preparations. Each culture dish contained $3 \times 10^{8}$ responder lymphocytes in $3 \mathrm{ml}$ of culture medium with antibiotics (31). Average $\left[{ }^{3} \mathrm{H}\right]$ thymidine incorporation by responder lymphocytes from three normal subjects that were stimulated with irradiated test leukocytes was recorded during the 7th day of culture; stimulation in each culture was with $3 \times 10^{8}$ target lymphocytes. Incorporation was corrected for efficiency, disentigrations per minute calculated, and results expressed as picocuries of ${ }^{3} \mathrm{H}$ incorporated.

Elsewhere cultures were on MNL preparations in flatbottomed microtiter plates (1S-FB-96-TC, Linbro Chemical Co., New Haven, Conn.). Cultures were usually prepared in triplicate; each culture contained 100,000 responder lymphocytes; $0.05 \mathrm{ml}$ plasma autologous to the responder lymphocytes and $0.15 \mathrm{ml}$ of culture medium with antibiotics (31). We measured incorporation from $2 \mu \mathrm{Ci}$ of $\left[{ }^{3} \mathrm{H}\right]$ thymidine (sp act: $5 \mathrm{Ci} / \mathrm{mmol}$, Schwarz/Mann Div.. Becton, Dickinson \& Co., Orangeburg, N. Y.) which was added to each culture for the last $24 \mathrm{~h}$ of incubation; cultures were in a humidified incubator enriched with $5 \% \mathrm{CO}_{2}$. At the end of the culture period (which lasted for 7 days except where specified), cells were harvested on to glass fiber filter paper and washed with saline using a multiple sample microprecipitator (Otto Hiller Co., Madison, Wis.). The cells were then solubilized with $0.25 \mathrm{ml}$ of NCS fluid (Amersham/Searle Corp., Arlington Heights, Ill.) ; $4 \mathrm{ml}$ of liquid scintillation fluid (30) was added $>1 \mathrm{~h}$ later and incorporation measured in a liquid scintillation counter with an external standard. Plasma from each test patient and normal subject was routinely tested in culture medium for its capacity to support MLR responses (32). Responder MNL from normal donors $A$ and $B$ were also tested in concomitant cultures for their ability to respond in the MLR using target $\mathrm{MNL}_{\mathbf{x}}$ from a third normal individual. 
TABLE I

MLR Stimulation by $M N L_{\mathbf{x}}$ (Group A) and by Irradiation Leukocytes (Group B) from 30 Patients with Hodgkin's Disease

\begin{tabular}{rrrlrl}
\hline $\begin{array}{c}\text { Patient } \\
\text { no. }\end{array}$ & $\begin{array}{c}\text { Clinical } \\
\text { stage }\end{array}$ & $\begin{array}{c}\text { Class B } \\
\text { symptoms }\end{array}$ & \multicolumn{1}{c}{ Tumor histology } & Therapy & $\begin{array}{r}\text { MLR } \\
\text { stimulation }\end{array}$ \\
\hline Group A & & & & & Mpm \\
& & & & 0 & 0 \\
1 & IV & + & Mixed cellularity & 0 & 0 \\
2 & III & + & Lymphocyte depletion & 0 & 0 \\
3 & III & 0 & Mixed cellularity & 0 & 4,300 \\
4 & IV & + & Lymphocyte depletion & 0 & 5,400 \\
5 & IV & + & Mixed cellularity & 0 & 10,000 \\
6 & IV & 0 & Lymphocyte depletion & 0 & 15,600 \\
7 & I & 0 & Mixed cellularity & 0 & 18,600 \\
8 & III & + & Nodular sclerosis & + & 18,700 \\
9 & III & + & Mixed cellularity & 0 & 35,400 \\
10 & II & 0 & Nodular sclerosis & 0 & 38,100 \\
11 & III & + & Nodular sclerosis & 0 & 40,900 \\
12 & III & 0 & Mixed cellularity & 0 & 41,100 \\
13 & II & 0 & Nodular sclerosis & 0 & 45,000 \\
14 & I & 0 & Nodular sclerosis & 0 & 61,500 \\
15 & I & 0 & Lymphocyte predominant & + & 61,800 \\
16 & III & + & Mixed cellularity & 0 & 65,000 \\
17 & III & + & Nodular sclerosis & 0 & 92,800 \\
18 & II & + & Mixed cellularity & & 0
\end{tabular}

Lowest value recorded in 50 control experiments $\quad 28,000$

$\begin{array}{crrlrl}\text { Group B } & & & & & p C i \\ 19 & \text { IV } & + & \text { Mixed cellularity } & 0 & 0.2 \\ 20 & \text { IV } & + & \text { Lymphocyte depletion } & + & 0.2 \\ 21 & \text { IV } & + & \text { Lymphocyte depletion } & 0 & 0.7 \\ 22 & \text { IV } & + & \text { Lymphocyte depletion } & 0 & 0.8 \\ 23 & \text { III } & + & \text { Lymphocyte depletion } & 0 & 1.2 \\ 24 & \text { III } & 0 & \text { Mixed cellularity } & 0 & 1.3 \\ 25 & \text { III } & + & \text { Mixed cellularity } & 0 & 1.6 \\ 26 & \text { III } & 0 & \text { Nodular sclerosis } & 0 & 7.2 \\ 27 & \text { III } & + & \text { Mixed cellularity } & 0 & 9.1 \\ 28 & \text { IV } & + & \text { Mixed cellularity } & + & 12.9 \\ 29 & \text { II } & 0 & \text { Nodular sclerosis } & 0 & 14.7 \\ 30 & \text { II } & 0 & \text { Nodular sclerosis } & 0 & 45.3\end{array}$

$T$ and $B$ cell identification. These tests were done on MNL preparations. $T$ cells were identified by rosette formation with neuraminidase-pretreated sheep erythrocytes at $4^{\circ} \mathrm{C}$ (33). B cells were identified by the presence of surface immunoglobulin using an immunofluorescence technique (34) and polyvalent antiserum to human immunoglobulins ( $\mathrm{Me}$ loy Laboratories Inc., Springfield, Va.).

Serologic tissue typing. We tested for $26 \mathrm{HL}-\mathrm{A}$ and workshop specificities by the microcytotoxicity test (35) using antisera obtained from the National Institutes of Health tissue typing bank plus well-defined antisera characterized locally or obtained by donation from other investigators.

Statistical analysis. The Wilcoxon rank sum test and the $\chi^{2}$ test were used to determine the significance of differences in results between paired sets of data.

\section{RESULTS}

Survey of MLR stimulation. MLR stimulation tests were performed on 30 patients with Hodgkin's disease, 17 with chronic lymphocytic leukemia, 13 with lymphocytic lymphoma, and 1 with the Sézary syndrome. The lowest result recorded in 50 control experiments using the microtiter plate culture system (group A) and in 50 other control experiments using the petri dish culture system (32) (group B) are listed in Table I. We tested MLR stimulation with MNLx (group A) or irradiated leukocytes (group B) from 30 patients with Hodgkin's disease. In this survey, sub- 
TABLE II

Clinical Status and Capacity for MLR Stimulation

\begin{tabular}{|c|c|c|c|c|c|c|}
\hline \multirow[b]{2}{*}{ Patient } & \multicolumn{3}{|c|}{ First test } & \multirow{2}{*}{$\begin{array}{l}\text { Months } \\
\text { between } \\
\text { tests }\end{array}$} & \multicolumn{2}{|l|}{ Second test } \\
\hline & Clinical stage & Histology & cpm* & & Clinical change & cpm* \\
\hline 1 & IIIB & Lymphocyte depleted & 22,200 & 12 & Considerable deterioration & 0 \\
\hline 2 & IVB & Mixed cellularity & 0 & $<1$ & Early response to therapy & 24,700 \\
\hline 3 & IIIB & Lymphocyte depleted & 0 & 18 & In remission & 84,500 \\
\hline 4 & IVB & Mixed cellularity & 5,400 & 7 & In remission & 55,200 \\
\hline 5 & IA (?) & Mixed cellularity & 15,600 & 2 & Asymptomatic & 54,200 \\
\hline 6 & IIIB & Nodular sclerosis & 18,600 & 16 & In remission & 58,800 \\
\hline
\end{tabular}

* $\left[{ }^{3} \mathrm{H}\right]$ Thymidine incorporation by normal MNL stimulated with patient MNLx.

normal stimulation was recorded on 16 patients although responder lymphocytes in all tests were from normal allogeneic individuals. Overall, results recorded on these patients differed significantly from our control experience $\left(\chi^{2} 7.32, P<0.01\right)$. Subnormal MLR stimulation was demonstrated on 15 out of 22 patients with clinical stage III or IV disease but on only 1 out of 8 other patients with stage I or II involvement. Irradiated cells from 11 out of 16 patients with symptomatic or class B Hodgkin's disease (24), but from only 5 out of 14 patients with asymptomatic disease, stimulated subnormally. Cells from 14 out of 19 patients with tumors of mixed cellularity or lymphocytedepleted histology, but from only 1 out of 10 patients with lymphocyte predominant or nodular sclerotic tumors, stimulated subnormal MLR responses. MNLx from the patient with the Sézary syndrome stimulated only $4,200 \mathrm{cpm}$ of $\left[{ }^{3} \mathrm{H}\right]$ thymidine incorporation. This

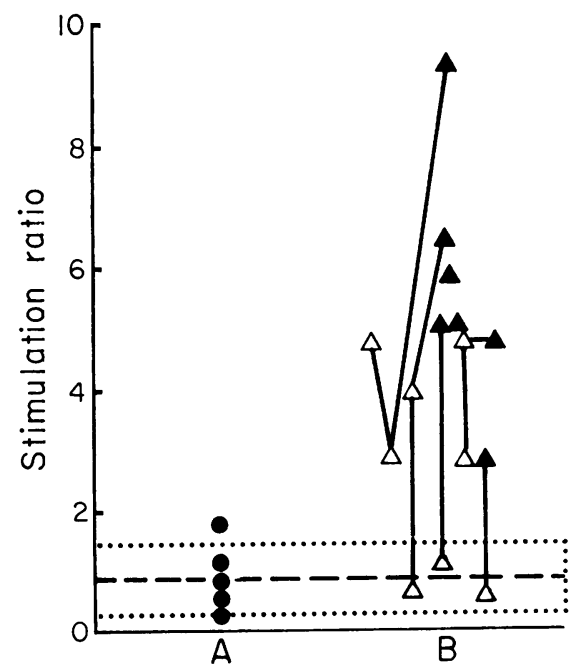

Figure 1 Stimulation ratios. Dashed line represents the mean and dotted lines represent $95 \%$ confidence limits on 50 control tests. $(\bullet, \Delta)$ Ratios on patients when first tested; $(\Delta)$ ratios on patients when retested. Ratios on individual patients are connected by solid lines. abnormality was not demonstrated on any patient with chronic lymphocytic leukemia or lymphocytic lymphoma.

Disease activity and MLR stimulation. MNL× from a patient with stage IIIB Hodgkin's disease of lymphocyte-depleted histology stimulated normal allogeneic MNL to incorporate $22,200 \mathrm{cpm}$ of $\left[{ }^{3} \mathrm{H}\right]$ thymidine when first tested; his MNLx were unable to stimulate an MLR response after his disease had progressed further over the subsequent 12 mo (Table II). Conversely, MNLx from five other patients stimulated subnormal MLR responses when first diagnosed but stimulated brisk responses after their clinical conditions had improved with conventional therapy. A recovered capacity for MLR stimulation was observed on patient 2 after only 3 wk of chemotherapy.

Stimulation ratios. A normal range of ratios was obtained from MLR tests on 50 normal individuals (mean ratio $\pm \mathrm{SD}: 0.83 \pm 0.22$ ). The results showed that MLR stimulation with the two protocol numbers of target cells is normally about comparable. Normal or near normal stimulation ratios were also recorded on five patients with Hodgkin's disease whose capacity for MLR activation had never been subnormal (Fig. 1A). In contrast, the lesser number of target cells from seven other patients with more extensive Hodgkin's disease stimulated significantly brisker MLR responses than did the higher number of target cells $(P<0.01)$; this is reflected in higher stimulation ratios (Fig. 1B, closed triangles). Most group B patients were retested after their clinical conditions had improved with chemotherapy; stimulation ratios were then at or closer to the normal range (Fig. 1B, open triangles).

MLR suppression by patient cells. The inverse relationship between MLR activation and the number of target cells per culture from selected patients with Hodgkin's disease suggested that MNL from these patients may have inhibited the reaction. We applied two techniques used by Folch and Waksman to remove suppressor activity from rat spleen cells $(27,30)$ to test this possibility. Five patients with Hodgkin's dis- 
TABLE III

Manipulations of $M N L_{\mathbf{x}}$ Aimed at Removing Suppressor_Cell Activity

\begin{tabular}{|c|c|c|c|c|c|c|}
\hline & \multicolumn{3}{|c|}{$100,000 \mathrm{MNL} \mathrm{L}_{\mathbf{x}}$} & \multicolumn{3}{|c|}{$200,000 \mathrm{MNL} x$} \\
\hline & $\begin{array}{c}\text { Not } \\
\text { preincubated }\end{array}$ & $\begin{array}{c}\text { Cyclo- } \\
\text { heximide }\end{array}$ & Glass wool & $\begin{array}{c}\text { Not } \\
\text { preincubated }\end{array}$ & $\begin{array}{l}\text { Cyclo- } \\
\text { heximide }\end{array}$ & Glass wool \\
\hline \multicolumn{7}{|c|}{ cpm $\left[{ }^{3} \mathrm{H}\right]$ thymidine incorporated } \\
\hline $1 \mathrm{a}$ & 37,300 & 71,600 & 89,700 & 13,100 & 10,900 & 111,800 \\
\hline $\mathrm{b}$ & 14,600 & - & 44,200 & 3,000 & - & 85,000 \\
\hline 2 & 39,800 & 39,400 & 30,000 & 15,400 & 64,700 & 28,700 \\
\hline 3 & 51,000 & 29,400 & 28,500 & 17,000 & 34,900 & 42,800 \\
\hline 4 & 52,900 & 57,500 & - & 8,900 & 56,900 & - \\
\hline 5 & 74,300 & 76,500 & 51,400 & 26,000 & 15,300 & 62,500 \\
\hline
\end{tabular}

ease whose cells had some capacity for MLR stimulation were studied. Stimulation with 100,000 MNL-lymphocytes from one patient was increased by preincubation with glass wool or cycloheximide (Table III, patient I). Stimulation with the same number of target cells from the other four patients was brisk and was not increased by either preincubation. Stimulation was low by 200,000 untreated target cells per culture from each of the five patients; this was markedly increased after preincubation of cells from the same MNL preparations with glass wool, cycloheximide, or both. In control experiments, preincubation of target MNL did not materially alter their subsequent capacity for MLR activation and did not increase spontaneous $\left[{ }^{3} \mathrm{H}\right]$ thymidine incorporation when pretreated cells were cultured with autologous lymphocytes.

Experiments were done to determine whether MLR suppression was caused by patient lymphocytes or monocytes. Stimulation was with 200,000 lymphocytes per culture. Phagocytic cells were removed using a method which provides minimal opportunity for cytoadherence because earlier tests indicated that cells which suppressed MLR responses were removed by adherence to

TABLE IV

Removal of Phagocytic Cells and MLR Stimulation*

\begin{tabular}{lcc}
\hline Donor of stimulating cells & MNL & $\begin{array}{c}\text { Irradiated } \\
\text { purified } \\
\text { lymphocytes }\end{array}$ \\
\hline Patient 1 & $c p m$ [ $\left.{ }^{3} H\right]$ thymidine & incorporation \\
Patient 2 & - & 1,100 \\
Patient 3 & - & 6,400 \\
Normal subject 1 & 38,900 & 12,700 \\
Normal subject 2 & 46,300 & 58,100 \\
Normal subject 3 & 59,900 & 51,900 \\
Normal subject 4 & 83,300 & 41,700 \\
\hline
\end{tabular}

* Stimulating cells included 200,000 lymphocytes per culture. foreign surfaces (Table III). In control experiments, irradiated lymphocytes stimulated as well as MNLx from the same cell collections (Table IV) and responder MNL included sufficient monocytes to mediate the responses (31). Similar studies were performed on three patients with Hodgkin's disease whose MNLx stimulated subnormally in the MLR. The results indicated that removing most monocytes did not increase the capacity for MLR activation by patient cells.

$M L R$ responses with Hodgkin's disease. A normal range of MLR responses in our two culture systems was determined from 150 control experiments. MLR responses were compared with MLR stimulation by the same MNL or leukocyte preparations from 26 patients with Hodgkin's disease when they were first tested. Cells from 10 of these patients both stimulated and responded subnormally. In four tests, stimulation was subnormal while MNL from the same patient preparations responded normally. Conversely, responses by cells from three patients were clearly deficient at a time when their MNLx stimulated allogeneic lymphocytes normally. Tests for MLR stimulation and responsiveness gave normal results on nine patients. The relationship between the capacity of MNL to stimulate and respond normally or subnormally was statistically significant (corrected $x^{2}: 3.27 ; P<0.05$ ).

Responses and stimulation using the two standard doses of target MNL-lymphocytes were compared on six selected patients with Hodgkin's disease whose cells clearly stimulated subnormal MLR responses when first tested and had entered clinical remission during the interval between testing (Table V). The $\left[{ }^{3} \mathrm{H}\right]-$ thymidine incorporation stimulated by 100,000 lymphocytes greatly exceeded that stimulated by $200,000 \mathrm{lym}-$ phocytes from the same patient MNLx preparations; this is reflected in a mean stimulation ratio of 5.2. Conversely, considerably more $\left[{ }^{3} \mathrm{H}\right]$ thymidine was incorporated by responder patient MNL, when stimulated 
TABLE V

Stimulation and Responses in the MLR with Different Numbers of Stimulating Cells

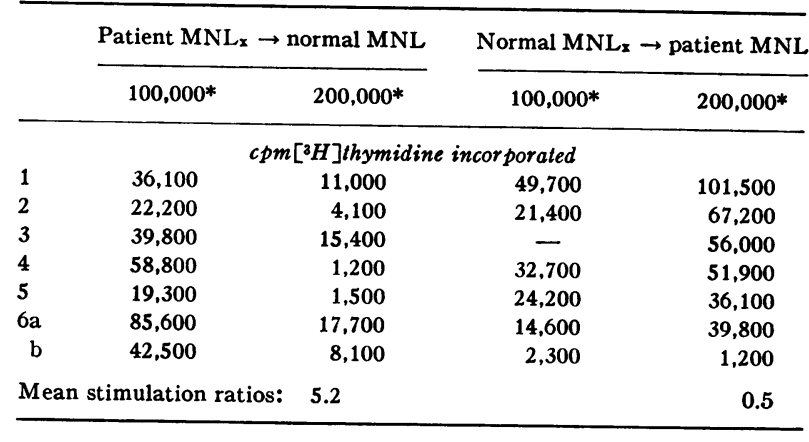

* Number of lymphocytes among MNLx added per culture.

with the higher than with the lower number of normal allogeneic target cells (mean stimulation ratio: 0.5 ).

Granulocyte suppression of the MLR. The survey for MLR stimulatory capacity on group $B$ patients (Table I) was performed using whole leukocyte preparations. Granulocytes are known to suppress MLR responses (36). It is possible that a relative excess of granulocytes, because of lymphopenia, contributed to the inability of irradiated leukocytes from some patients to stimulate normal MLR responses. However, other factors must have contributed to subnormal MLR stimulation by patient cells since MNLx preparations that included $<5 \%$ granulocytes from 9 out of 18 other patients (Table I, group A) also stimulated subnormal MLR responses.

Further experiments were done (a) to see if MLR stimulation with patient target cells is excessively susceptible to suppression by granulocytes, and $(b)$ to compare MLR suppression by patient and normal granulocytes. Irradiated granulocytes were added at predetermined concentrations to one-way-stimulating MLR cultures (Fig. 2). The effect of granulocytes from five patients with Hodgkin's disease upon stimulation by autologous MNLx (graph A) and by MNLx from normal donors (graph B) was compared with results in similar experiments where all cell preparations were from normal individuals (graph $\mathrm{C}$ ). The presence of $2 \times 10^{\circ}$ and, to a lesser degree, $1 \times 10^{\circ}$, granulocytes per $0.2 \mathrm{ml}$ culture volume inhibited all MLR responses. Cultures using normal target cells were not inhibited by $0.5 \times 10^{\circ}$ of either patient (graph B) or normal (graph C) granulocytes. In contrast, this concentration of granulocytes significantly inhibited MLR responses when stimulation was with patient MNLx $(P<0.01)$. Thus granulocytes at concentrations of only $2.5 \times 10^{\circ}$ per $1 \mathrm{ml}$ culture volume suppressed MLR activation by patient MNLx.

Identification of $T$ and $B$ lymphocytes. A patient with Hodgkin's disease was tested when her MNLx gave an elevated MLR stimulation ratio of 5.12. Only $6 \%$ of lymphocytes from this cell preparation were identified as $\mathrm{T}$ cells; $42 \%$ had surface immunoglobulin. Normally, this laboratory identifies $\geq 88 \%$ of MNLlymphocytes as $\mathrm{T}$ or $\mathrm{B}$ cells; the identity of $52 \%$ of lymphocytes from this patient preparation could not be determined. Although on cyclophosphamide therapy at the time, her blood had a normal complement of $\mathbf{B}$ cells (patient: 378 , normal range: $310-830$ per $\mathrm{mm}^{8}$ of blood).

Miscellaneous studies. Mitomycin C-pretreated MNL as well as MNLx from selected patients with Hodgkin's disease stimulated subnormal MLR responses. Responses stimulated with patient MNLx were subnormal after 4 and 9 days as well as after the standard 7 days of incubation. Culture media in these tests contained plasma from normal subjects and not from patients. Patient plasmas were also tested routinely for MLR suppression; none was inhibitory. Pretreatment with protease or neuraminidase or overnight preincubation did not improve the capacity of patient MNLx for MLR stimulation. Serologic tissue typing was performed on three patients with Hodgkin's disease and subnormal MLR stimulation and upon 13 of their first degree relatives. The HL-A antigens identified on patient lymphocytes were compatible with those expected from family inheritance patterns. In this limited survey, subnormal MLR stimulation was not associated with any particular pattern of HL-A antigens.

"Three-way" MLR cultures were prepared in which normal responder MNL were cultured with the lesser stimulating number of allogeneic normal target cells plus patient MNLx. Rodey, Sprader, and Bortin were

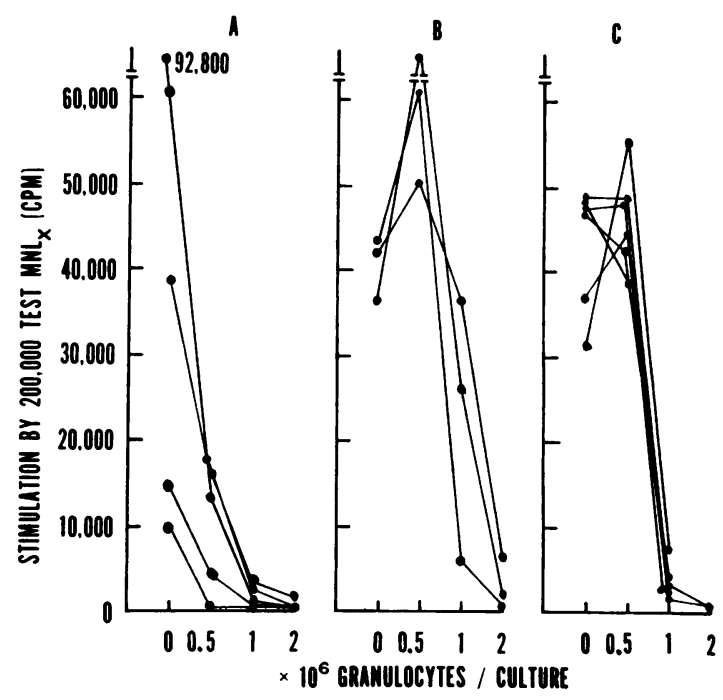

FIgure 2 The effect of granulocytes upon MLR stimulation. 
able to confirm MLR suppression by leukemic AKR mouse spleen cells using this system (23). The presence of $100,000 \mathrm{MNLx}$-lymphocytes from three patients with Hodgkin's disease and subnormal MLR stimulation did not inhibit the response. This may reflect alteration in the density of patient cells with MLR suppressive potential relative to other cells that participated in the MLR responses. This test system was technically not feasable using higher numbers of patient MNLs.

\section{DISCUSSION}

Peripheral blood leukocytes from 16 out of 30 patients with Hodgkin's disease did not stimulate allogeneic lymphocytes to incorporate a normal amount of $\left[{ }^{3} \mathrm{H}\right]$ thymidine in the MLR. In contrast, leukocytes from 30 other patients with chronic lymphocytic leukemia or lymphocytic lymphoma did stimulate normal responses. Subnormal MLR stimulation was observed most often in patients with extensive, symptomatic Hodgkin's disease with prognostically unfavorable tumor histology. This abnormality disappeared after patients responded to therapy which suggests that its presence was related to the Hodgkin's disease.

In certain cases, MLR stimulation was inversely related to the number of patient cells added to cultures. The possibility that this represented inhibition. of MLR responses by the higher concentration of patient MNL. was supported in subsequent experiments. When manipulations which remove suppressor cell activity $(27,30)$ were applied to MNL from selected patients with Hodgkin's disease, subsequent MLR stimulation by these cells was greatly increased. The inhibiting cells were probably lymphocytes since removal of phagocytic cells did not increase low MLR stimulation. This mechanism for MLR suppression differs from that previously reported with Hodgkin's disease (19) and with systemic lupus erythematosis (37) in that patient plasma supported normal MLR responses in the present study. Suppression of MLR responses with systemic lupus erythematosis appears to be caused by circulating antibody to components of (probably responder) T-cell membranes. The MLR suppression that is the subject of the present report appears to be related to the actual presence of patient lymphocytes.

It is known that a polymorphonuclear leukocytosis suppresses delayed hypersensitivity in vivo (38) and an excess of granulocytes inhibits the MLR in vitro (36). In the present study, granulocytes amplified MLR suppression caused by lymphocytes from patients with Hodgkin's disease. As few as $2.5 \times 10^{\circ}$ granulocytes per $1 \mathrm{ml}$ inhibited MLR responses stimulated with MNLx from selected patients. Perhaps, physiologic concentrations of granulocytes may also contribute to the overall immunodeficiency with Hodgkin's disease by suppressing immune response in vivo. Granulocytes from patients with Hodgkin's disease were not excessively inhibitory of the MLR.

Other mechanisms that might contribute to subnormal MLR stimulation with Hodgkin's disease were investigated: The use of irradiation to achieve one-way stimulation was not responsible for the abnormality. The duration of incubation for optimal MLR stimulation was not altered when target lymphocytes were from patients with Hodgkin's disease. No evidence was found that areas on leukocyte membranes that participate in MLR activation were sequestered by membrane coating. The expression of serologically defined histocompatibility markers on patient lymphocytes was normal as determined by inheritance patterns of HL-A antigens. However, there remains a possibility that other membrane sites specific for MLR activation may be defective. The high frequency of subnormal MLR stimulation with advanced Hodgkin's disease, using responder lymphocytes from at least two normal individual per test, makes lymphocyte defined histocompatibility an unlikely overall possibility (39). Monocytes from patients with Hodgkin's disease adequately support macrophage-dependent lymphoproliferative responses such as the $\operatorname{MLR}(21,40)$.

Waldmann et al. have recently reported that $T$ cells from some patients with common variable immunoglobulin deficiency suppress immunoglobulin secretion by normal lymphocytes (41). This abnormality, which also illustrates the heterogeneity of common variable immunoglobulin deficiency (42), serves as a model for suppressor T-cell hyperactivity. The present study adds Hodgkin's disease as a second disorder which manifests suppressor lymphocyte hyperactivity. Humoral immunity is considerably less depressed than cell-mediated immunity with advanced Hodgkin's disease (10, 11). Conversely, cell-mediated immunity is less severely impaired than humoral immunity with common variable immunoglobulin deficiency (43). Perhaps perturbations of immunoregulatory mechanisms with Hodgkin's disease and common variable immunoglobulin deficiency are qualitatively different.

Edelson et al. have reported that mitomycin C-pretreated leukocytes, from one out of four patients with the Sézary syndrome, stimulated subnormally in the MLR (22). In the present study, MNLx from another patient with the Sézary syndrome stimulated subnormal responses. Rodey et al. have reported that spleen cells from leukemic AKR mice also suppress MLR responses (23). Current evidence suggests that both the Sézary syndrome and AKR leukemia are $\mathrm{T}$-cell neoplasms (44-46). Subnormal MLR activation with predominantly neoplastic $\mathrm{T}$-cell preparations may reflect a poor capacity of $\mathrm{T}$ cells to stimulate allogeneic lym- 
phocytes in the presence of diluted numbers of B cells. Alternatively, these neoplasms may represent malignant proliferation of a clone of suppressor $\mathrm{T}$ cells.

While the Sézary syndrome and AKR murine leukemia are clearly lymphoproliferative neoplasms, Hodgkin's disease is a lymphocyte depleting disorder. Therefore, high suppressor lymphocyte activity with Hodgkin's disease may be relative because of a quantitative imbalance of normal lymphocyte populations and not due to proliferation of an excess of suppressor lymphocytes. Such an imbalance could result from effector $T$ cells being principally depleted with progressive Hodgkin's disease. Studies on B- and T-cell percentages among MNL from one of our patients illustrates selective depletion of $\mathrm{T}$ cells with advanced Hodgkin's disease. Both normal (47) and neoplastic (48) B cells can stimulate brisk $\left[{ }^{3} \mathrm{H}\right]$ thymidine incorporation by allogeneic lymphocytes. The normal number of B cells among MNLx from this patient supports other evidence that subnormal MLR stimulation with Hodgkin's disease is due to suppression of the response rather than a deficit of cells with stimulatory capacity.

An overall relationship was demonstrated between subnormal MLR activation and responsiveness by MNL from patients with advanced Hodgkin's disease. Maximum responses by patient lymphocytes was only achieved with high numbers of normal target cells which is compatible with Hodgkin's disease having a particularly adverse effect upon effector $T$ cells as are other manifestations of cell-mediated immune impairment (2-11). The fact that humoral immunity is rarely deficient with Hodgkin's disease $(10,11)$ suggests that helper $T$ cells as well as the B-cell series are not severely depleted in these patients. The present study suggests that suppressor lymphocytes are not depleted and may be present in excessive concentrations. This suppression and deficit of effector $T$ cells may be further compounded by suppression of immune responses by granulocytes.

Chronic lymphocytic leukemia and lymphocytic lymphoma are predominantly B-cell neoplasms (49-51). Current evidence suggests that suppressor lymphocytes are predominately $\mathrm{T}$ cells $(16,41,52,53)$. It is therefore not surprising that subnormal MLR stimulation was not observed in the present study on any of 30 patients with chronic lymphocytic leukemia or lymphocytic lymphoma where according to published experience (49-51) the majority of neoplasms are of the B-cell series.

At present there is no method available for identifying and quantitating suppressor $\mathrm{T}$ cells. The in vitro method described by Waldmann et al. (41) is useful for measuring suppressor $T$-cell activity upon humoral immune responses. The techniques used in the present study permit functional studies on suppressor $T$ cells in a response that is predominantly by effector $\mathrm{T}$ cells (47). Both procedures offer the advantage of measuring responses by healthy immunocytes which are un. affected by disease processes under evaluation.

\section{ACKNOWLEDGMENTS}

We are grateful to Roger Rossen, M.D., for helpful suggestions, to Jack Thornby, Ph.D., for assisting with statistical analyses, and to Ms. LaDonna McClain for help in preparing the manuscript.

This work was supported in part by National Institutes of Health grant 1RO1CA1610A-01 and grants from the Kelsey-Leary Foundation and the Adelene Favela Fund.

\section{REFERENCES}

1. Lukes, R. J., and J. J. Butler. 1966. The pathology and nomenclature of Hodgkin's disease. Cancer Res. 26: 1063-1083.

2. Young, R. C., M. P. Corder, H. A. Haynes, and V. T. DeVita. 1972. Delayed hypersensitivity in Hodgkin's disease. A study of 103 untreated patients. Am. J. Med. $52:$ 63-72.

3. Aisenberg, A. C. 1962. Studies on delayed hypersensitivity in Hodgkin's disease. J. Clin. Invest. 41: 1964 1970.

4. Hersh, E. M., and J. J. Oppenheim. 1965. Impaired in vitro lymphocyte transformation in Hodgkin's disease. N. Engl. J. Med. 273: 1006-1012.

5. Aisenberg, A. C. 1965. Quantitative estimation of the reactivity of normal and Hodgkin's disease lymphocytes with thymidine-214C. Nature (Lond.). 205: 1233-1235.

6. Han, T., and J. E. Sokal. 1970. Lymphocyte response to phytohemagglutinin in Hodgkin's disease. Am. J. Med. 48: 728-734.

7. Matchett, K. M., A. T. Huang, and W. B. Kremer. 1973. Impaired lymphocyte transformation in Hodgkin's disease. Evidence for depletion of circulating T-lymphocytes. J. Clin. Invest. 52: 1908-1917.

8. Levy, R., and H. S. Kaplan. 1974. Impaired lymphocyte function in untreated Hodgkin's disease. N. Engl. J. Med. 290: 181-186.

9. Gotoff, S. P., S. Lolekha, M. Lopata, J. Kopp, R. L. Kopp, and T. J. Malecki. 1973. The macrophage aggregation assay for cell-mediated immunity in man. Studies of patients with Hodgkin's disease and sarcoidosis. $J$. Lab. Clin. Med. 82: 682-691.

10. Chase, M. W. 1966. Delayed-type hypersensitivity and the immunology of Hodgkin's disease, with a paralle examination of sarcoidosis. Cancer Res. 26: 1097-1120.

11. Aisenberg, A. C. 1965. Quantitative estimation of the reactivity of normal and Hodgkin's disease lymphocytes with thymidine-2-14C. Nature (Lond.). 205: 1233-1235.

12. Casazza, A. R., C. P. Duvall, and P. P. Carbone. 1966. Infection in lymphoma. Histology, treatment, and duration in relation to incidence and survival. JAMA ( $J$. Am. Med. Assoc.). 197 : 710-724.

13. Smith, J. L., D. C. Cowling, and C. R. Barker. 1972. Response of lymphocytes in chronic lymphocytic leukaemia to plant mitogens. Lancet. 1: 229-233.

14. Seligmann, M., and J. C. Brouet. 1973. Antibody activity of human myeloma globulins. Semin. Hematol. 10: 163177.

15. Kappler, J. W., P. C. Hunter, D. Jacobs, and E. Lord. 1974. Functional heterogeneity among the T-derived lymphocytes of the mouse. I. Analysis of adult thymectomy. J. Immunol. 113: 27-38. 
16. Gershon, R. K. 1974. T cell control of antibody production. Contemp. Top. Immunobiol. 111: 1-40.

17. Nelson, D. S. 1973. Production by stimulated macrophages of factors depressing lymphocyte transformation. Nature (Lond.). 246: 306-307.

18. Arpels, C., and C. M. Southam. 1969. Cytotoxicity of sera from healthy persons and cancer patients. Int. J. Cancer. 4: 548-559.

19. Gaines, J. D., M. A. Gilmer, and J. S. Remington. 1973. Deficiency of lymphocyte antigen recognition in Hodgkin's disease. Natl. Cancer Inst. Monogr. 36: 117121.

20. Twomey, J., C. Douglass, and S. Norris. 1973. Failure of leukocytes in Hodgkin's disease to stimulate a mixed leukocyte reaction (MLR). Proc. Leucocyte Cult. Conf. $7: 627-642$

21. Twomey, J. J., C. C. Douglass, and S. M. Morris. 1973. Inability of leukocytes to stimulate mixed leukocyte reactions. J. Natl. Cancer Inst. 51: 345-351.

22. Edelson, R. L., C. H. Kirkpatrick, E. M. Shevach, P. S. Schein, R. W. Smith, I. Green, and M. Lutzner. 1974. Preferential cutaneous infiltration by neoplastic thymusderived lymphocytes. Morphologic and functional studies. Ann. Intern. Med. 80: 685-692.

23. Rodey, G. E., J. C. Sprader, and M. M. Bortin. 1974. Inhibition of normal allogeneic responder cells in mouse mixed leukocyte culture by long-passage AKR leukemic lymphoblasts. Cancer Res. 34: 1289-1294.

24. Rosenberg, S. A. 1966. Report of the committee on the staging of Hodgkin's disease. Cancer Res. 26: 1310.

25. Böyum, A. 1968. Isolation of mononuclear cells and granulocytes from human blood. Isolation of mononuclear cells by one centrifugation, and of granulocytes by combining centrifugation and sedimentation at Ig. Scand. J. Clin. Lab. Invest. Suppl. 97: 77-89.

26. Bach, F. H., and N. K. Voynow. 1966. One-day stimulation in mixed leukocyte cultures. Science (Wash. D. C.). 153: 545-547.

27. Folch, H., and B. H. Waksman. 1974. The splenic suppressor cell. I. Activity of thymus-dependent adherent cells : changes with age and stress. J. Immunol. 113: 127-139.

28. Woodruff, J. J., and B. M. Gesner. 1969. The effect of neuraminidase on the fate of transfused lymphocytes. J. Exp. Med. 129: 551-567.

29. Brody, J. T. 1972. Augmentation of leukemic lymphocyte reactivity to phytohemagglutinin by salivary receptor. Blood. 40: 70-76.

30. Folch, H., and B. H. Waksman. 1974. The splenic suppressor cell. II. Suppression of the mixed lymphocyte reaction by thymus-dependent adherent cells. $J$. Immunol. 113: 140-144.

31. Twomey, J. J., O. Sharkey, Jr., J. A. Brown, A. H. Laughter, and P. H. Jordan, Jr. 1970. Cellular requirements for the mitotic response in allogeneic mixed leukocyte cultures. J. Immunol. 104: 845-853.

32. Twomey, J. J., and O. Sharkey. 1972. An adaptation of the mixed leukocyte culture test for use in evaluating lymphocyte and macrophage function. J. Immunol. 108: 984-990.

33. Weiner, M. S., C. Bianco, and V. Nussenzweig. 1973. Enhanced binding of neuraminidase-treated sheep erythrocytes by human T lymphocytes. Blood. 42: 939-946.

34. Rabellino, E., S. Colon, H. M. Grey, and E. M. Unanue. 1971. Immunoglobulins on the surface of lymphocytes. I. Distribution and quantitation. J. Exp. Med. 133: 156167.
35. Mittal, K. K., M. R. Mickey, D. P. Singalard, and P. I. Terasaki. 1968. Serotyping for homotransplantation. XVIII. Refinement of microdroplet lymphocyte cytotoxicity test. Transplantation. 6: 913-927.

36. Bain, B., and K. Pshyk. 1973. Reactivity in mixed cultures of mononuclear leukocytes separated on FicollHypaque. Proc. Leucocyte Cult. Conf. 7: 29-37.

37. Wernet, P., and H. G. Kunkel. 1973. Antibodies to a specific surface antigen of $\mathrm{T}$ cells in human sera inhibiting mixed leukocyte culture reactions. J. Exp. Med. 138: $1021-1026$.

38. Heiss, L. I., and D. L. Palmer. 1974. Anergy in patients with leukocytosis. Am. J. Med. 56: 323-332.

39. Cepellini, R., and J. J. van Rood. 1974. The HL-A system. I. Genetics and molecular biology. Sem. Hematol. $11: 233-251$.

40. Blaese, R. M., J. J. Oppenheim, R. C. Seeger, and T. A. Waldmann. 1972. Lymphocyte-macrophage interaction in antigen induced in vitro lymphocyte transformation in patients with Wiskott-Aldrich syndrome and other diseases with anergy. Cell. Immunol. 4: 228-242.

41. Waldmann, T. A., M. Durm, S. Broder, M. Blackman, R. M. Blaese, and W. Strober. 1974. Role of suppressor $\mathrm{T}$ cells in pathogenesis of common variable hypogammaglobulinaemia. Lancet. 2: 609-613.

42. Geha, R. S., E. Schneeberger, E. Merler, and F. S. Rosen. 1974. Heterogeneity of "acquired" or common variable agammaglobinemia. $N$. Engl. J. Med. 291: 1-6. 43. Douglas, S. D., L. S. Goldberg, and H. H. Fudenberg. 1970. Clinical, serologic and leukocyte function studies on patients with idiopathic "acquired" agammaglobinemia and their families. Am. J. Med. 48: 48-53.

44. Gross, L. 1960. Biological and pathogenic properties of a mouse leukemia virus. Acta Haematol. 23 : 259-275.

45. Barker, A. D., and S. D. Waksal. 1974. Thymus-derived lymphocyte differentiation and lymphocyte leukemias. Evidence for the existence of functionally different subpopulations of thymus-derived cells in leukemic AKR mice. Cell. Immunol. 12: 140-149.

46. Brouet, J-C., G. Flandrin, and M. Seligmann. 1973. Indications of the thymus-derived nature of the proliferating cells in six patients with Sézary's syndrome. N. Engl. J. Med. 289: 341-344.

47. Chess, L., R. P. MacDermott, and S. F. Schlossman 1974. Immunologic functions of isolated human lympho cyte subpopulations. II. Antigen triggering of $\mathrm{T}$ and $\mathrm{B}$ cells in vitro. J. Immunol. 113: 1122-1127.

48. Twomey, J. J., and C. C. Douglass. 1974. An in vitro study of lymphocyte and macrophage function with lymphoproliferative neoplasms. Cancer. 33: 1034-1038.

49. Preud'homme, J. L., and M. Seligmann. 1972. Surface bound immunoglobulins as a cell marker in human lymphoproliferative diseases. Blood. 40: 777-794.

50. Aisenberg, A. C., and K. J. Block. 1972. Immunoglobulins on the surface of neoplastic lymphocytes. N. Engl. J. Med. 287: 272-276.

51. Peter, C. R., M. R. MacKenzie, and F. J. Glassy. 1974. $\mathrm{T}$ or $\mathrm{B}$ cell origin of some non-Hodgkin's lymphomas. Lancet. 2 : 686-689.

52. Dutton, R. W. 1973. Inhibitory and stimulatory effects of concanavalin A on the response of mouse spleen cell suspensions to antigen. II. Evidence for separate stimulatory and inhibitory cells. J. Exp. Med. 138: 1496-1505.

53. Gerber, N. L., J. A. Hardin, T. M. Chused, and A. D. Steinberg. 1974. Loss with age in NZB/W mice of thymic suppressor cells in the graft-vs-host reaction. J. Immunol. 113: 1618-1625. 